\title{
Mobile Learning Platform for E-Learning
}

\author{
doi:10.3991/ijim.v3i3.678 \\ G.S. Chis, H. Grebla and L. Stanca \\ Babeş-Bolyai University, Cluj-Napoca, Romania
}

\begin{abstract}
The fast changing or the development of technologies induces the possibility to process the information in key moments in different locations. Thus, not only those who are learning need mobile tools for learning, but also the trainers need mobile tools for preparing the classes, for coordinating the educational activities. Using this background, new patterns had been developed based on its main principles, starting with the evolution of technology. Based on these modifications we are going to present a mobile-learning system which we intend to integrate with our E-learning system..
\end{abstract}

Index Terms-m-learning, GGSN, e-learning, students.

\section{PROBLEM DESCRIPTION}

Nowadays we are faced to a continuous development of technologies which determines great changes in all fields of activities. The expansion of the Internet network which allowed the access to information in a much shorter time and in a more elegant manner than in the past caused radical changes in the field of traditional learning. Thus, every individual has to accumulate information as fast as possible in order to perform daily activities.

The fast changing or the development of technologies induces the need to process the information in key moments, for short periods of time, in different locations. But not only those who are learning need mobile tools of learning, but also the learning process supervisors or trainers need mobile tools for preparing the classes, the exams, for coordination of the educational activities.[2]

The fact that TV sets appeared, then Internet Network and mobile telephony developed, has determined the elearning concept. Within this concept, depending on the access of the population to technology, other sub-models have been developed: blended learning, lifelong learning and last but not least mobile learning. Based on these modifications we are going to present here the necessary components to create a final product.

\section{SOLUTION DESCRIPTION}

\section{A. Introduction}

In April 2007 there were more than 2.5 billion total subscribers of various mobile technologies, and it is expected that worldwide mobile subscribers will reach close to 4 billion by 2010.[9]

In this specific industry field of mobile communication there are two challenges:

- adding new services or new user experiences for which mobile subscribers are willing to pay. For example, applications driven by the Third-Generation Partnership Project's (3GPP) IP Multimedia
Subsystem (IMS) architectural framework fall into this category.

- reducing operating expenses (OPEX). At the top of the list is the wireline infrastructure that mobile operators have to maintain regardless of whether they own or lease lines. This includes their core networks, since, for example, Mobile Switching Centers (MSCs) are connected through the Time-division multiplexing (TDM) infrastructure.[9]

Standards organizations as 3GPP (for GSM networks) and 3GPP2 (for CMDA networks) are actively involved in driving the development of next-generation wireless systems. The high level objective is to create high-speed broadband and IP-based mobile systems featuring network-to-network interconnection, feature/service transparency, global roaming, and seamless services independent of location. [9]

We deem necessary to create a mobile learning prototype because it represents a continuous way to develop both for the students and the employees. The development and realization of such a prototype would bring additional value to an e-learning as well as the access to the information one person may need any time it needs regardless the place it resides provided that has a PDA integrated in the platform our research proposes.

We consider an m-learning system from the conceptual, functional point of view and also from the point of view of the components $\left(\mathrm{GGSN}^{1}\right.$, PDAs, Smartphone's etc) with the purpose of offering a reliable solution that can work in educational system. In the article we will demonstrate, based on statistics, the need of an m-learning system as a continuation of distance learning system.

\section{B. Proposed architecture}

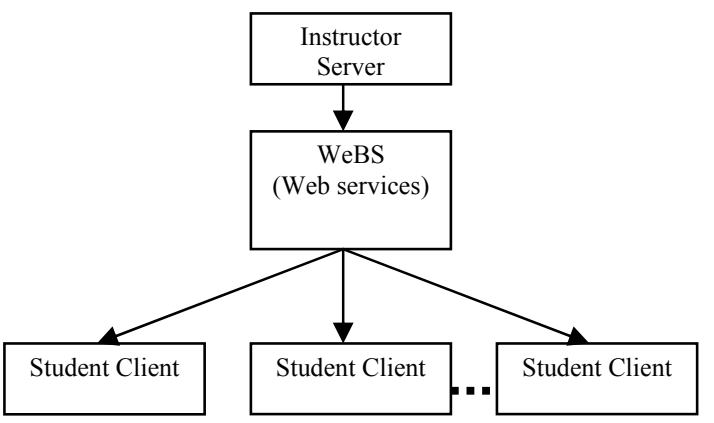

Figure 1. An E-Learning System

We consider that e-learning is critical to the success of the faculty and also of the students. It is a strong belief

${ }^{1}$ Gateway GPRS Support Node a key network element that will help GSM service provider migrate to all-IP networks in the wideband CDMA (WCDMA) world [6] 
that a Learning Content Management System will improve academic results and the direct involvement of the industry will bring a higher rate of employment for graduates.

To make e-learning successful, the technology must have several characteristics that make the learner's and the instructor's experience valuable and desirable to repeat. Based on that, we proposed [2] a model for e-learning that can easily be transformed to a m-learning product.

The 3 tier architecture is depicted in fig. 1 .

Our e-learning system mainly provides five functionalities for the trainer:

- Assists the academic trainer to lecture. The system provides the trainer a visualized graphic user interface GUI). Through the GUI, the trainer can easily know how many students are currently in the system. He/she can upload the lecture notes or questions and navigate between them. The system also presents visualized feedback information and statistic information, which can help the trainer adjust his lecture according to the responses of the class instantaneously.

- Allow industrial trainer to propose some summative test on some predefined directions of study (the main directions the students can take classes at the university)

- Interactions between academic trainer and students. These interactions include two parts: get students' answers to the questions and response back the results to students right away. In addition to that, the trainer can also get instant comments from students.

- Provide statistic information for the academic trainer. The statistic information can help the trainer to know how well the students perform in the class.

- Automatic evaluation to provide results for summative tests so that the employer can set the employment test levels for the new generation of graduates.

The model for the m-learning that we propose is based on GGSN technology. We found this technology suitable for us because it represents an Interface between the GPRS $^{2}$ wireless data network and other networks such as the Internet or private networks.[3] The GGSN is the anchor point that enables the mobility of the user terminal in the GPRS/UMTS ${ }^{3}$ networks. In essence, it carries out the role in GPRS equivalent to the Home Agent in Mobile IP. It maintains routing necessary to tunnel the Protocol Data Units (PDUs) to the $\mathrm{SGSN}^{4}$ that service a particular MS (Mobile Subscriber). Other functions include subscriber screening, IP Pool management and address mapping, QoS and PDP context enforcement.[4][5]

Third generation mobile radio communication systems can be connected to third generation radio access networks but also to private networks for small enterprises / domestic enterprises (SOHO). In order to maintain complete coverage of second hand services, terminals with dual mode can be connected to radio access networks

\footnotetext{
${ }^{2}$ General Packet Radio Service

${ }^{3}$ Universal Mobile Telecommunications System - is one of the thirdgeneration $(3 \mathrm{G})$ cell phone technologies, which is also being developed into a $4 \mathrm{G}$ technology. Currently, the most common form of UMTS uses W-CDMA.

${ }^{4}$ Serving GPRS Support Node
}

like for example GSM networks. These radio access networks are connected to fixed networks by[1]:

1) Interface $\mathbf{A}$ (as you can see in Figure 2) and the commutation center for MSC mobile network for services commuted in a circuit mode.

2) Interface $\mathbf{G b}$ (as you can see in Figure 2), service node for GPRS (SGSN) and gate node GPRS (GGSN) for package oriented services.

The main development direction that $3 \mathrm{G}$ supports is given by the appearance of new mobile terminals like:

1) Personal Digital Assistants (PDA);

2) Radio connected laptops (Wi-Fi, Bluetooth)

3) Terminals based on new radio technologies, for example based on the UTRA concept (WCDMA ${ }^{5}$ for FDD $^{6}$ and TD/CDMA for TDD).

The architecture of a $3 \mathrm{G}$ network is simple because it has to be easily integrated within other communication networks. From the point of view of the relationship between the user and $3 \mathrm{G}$ (for ex. UMTS) a main network will be defined as well as an access network. The main network is a fixed communication network, the one that students and teachers can use is a data transmission network PDN.

Access network is composed by a radio network controller. This has the role to manage the radio resources given to the access network and to organize and to supervise it and the radio nodes. The radio nodes represent the broadcasting reception equipment structured in conformity with the modulation and multiplexing techniques adopted.

The general conclusion is that UMTS, which represents the future of mobile communication for Europe, was developed within the European Union, closely related, from the technical point of view, to the systems developed by the Japanese industry. Together with the other systems from $3 \mathrm{G}$, it can ensure communication networks to a global level and a wide range of services, that have been operational starting 2002 and have been developing since 2005 with a prognosis to continue till 2010.

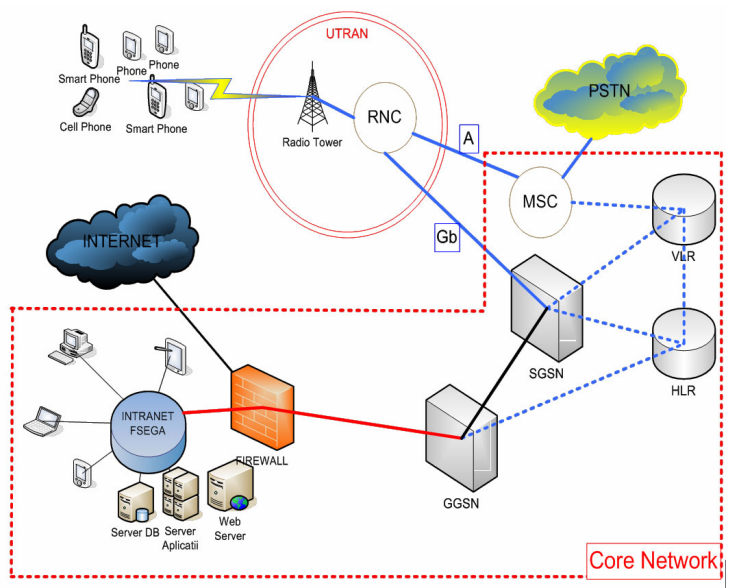

Figure 2. Our Intranet Model with GGSN

\footnotetext{
${ }^{5}$ Wideband Code Division Multiple Access is a type of $3 \mathrm{G}$ cellular network.

${ }^{6}$ Frequency Division Duplex
} 
The figure bellow represents how our model will function: UE (smart phones and mobile phones) will connect to our operator (FSEGA). FSEGA will be functional only during exam periods, the rest of the time we will rent it to the different operators (Vodafone, Orange, Zapp, Cosmote) depending on their needs (for example, for events in the nearby area that necessitate additional signal). Our students will connect through SGSN - GGSN into our intranet network to the webservices. After strong authentification in our platform, they will be able to start their exams.

The elements in Figure 2 represent:

RNC- Radio Network Controller

UTRAN, stands for UMTS Terrestrial Radio Access Network, is a collective term for the Node B's and Radio Network Controllers which make up the UMTS radio access network. This communications network, commonly referred to as $3 \mathrm{G}$ (for 3rd Generation Wireless Mobile Communication Technology), can carry many traffic types from real-time Circuit Switched to IP based Packet Switched. The UTRAN allows connectivity between the UE (Smart Phone, Mobile Phone) and the core network.

Visitor Location Register (VLR) is a database which stores information about all the mobiles that are currently under the jurisdiction of the MSC (Mobile Switching Center). The Home Location Register or HLR is a central database that contains details of each mobile phone subscriber that is authorized to use the GSM core network. There is one logical HLR per PLMN, although there may be multiple physical platforms.

The public switched telephone network (PSTN) is the network of the world's public circuit-switched telephone networks, in much the same way that the Internet is the network of the world's public IP-based packet-switched networks. Originally a network of fixedline analog telephone systems, the PSTN is now almost entirely digital, and now includes mobile as well as fixed telephones.

\section{STATISTICAL EXPERIMENT}

TABLE I.

STUDENT'S REORIENTATION ON THE MOBILE COMMUNICATIONS MARKET

\begin{tabular}{|c|c|c|c|}
\hline & $\begin{array}{c}\text { SMART } \\
\text { PHONES }\end{array}$ & PDA & $\begin{array}{c}\text { MOBILE } \\
\text { PHONES }\end{array}$ \\
\hline $\begin{array}{c}\text { SMART } \\
\text { PHONES }\end{array}$ & $0 \%$ & $15 \%$ & $20 \%$ \\
\hline PDA & $30 \%$ & $0 \%$ & $15 \%$ \\
\hline $\begin{array}{c}\text { MOBILE } \\
\text { PHONES }\end{array}$ & $35 \%$ & $20 \%$ & $0 \%$ \\
\hline
\end{tabular}

The speed in ours lives imposes the adaptation of educational process[18] to these conditions. This was made possible thanks to new technologies that appeared on the market. The e-learning model previously described could use SMART PHONES and/or PDA, mobile phones, to test the knowledge of students, avoiding in this way the necessity of a classroom. When matriculating to the university, each student provided data, necessary for us to conduct our statistic using the Markov chain.[17],[8]

Due to data obtained, we noticed the following percentage on the 2008's market: $25 \%$ Smart Phones, 30\%
PDAs and the rest of $45 \%$ mobile phones. The fidelity quote of buyers (students of our university) is constant: $65 \%$ faithful to Smart Phones, $55 \%$ to PDAs and $45 \%$ to mobile phones. The rest reorientates this way:

Next we will follow the evolution of those 3 products percentages during a period of 4 years. We start from the hypothesis that the probabilities of transition are constant. The statistic study will allow us to determine which of the products would be chosen by the students to assimilate and test their knowledge. Based on reorientation and the fidelity quote, we will realize the solution matrix for the 4 following years.

$$
M=\left(\begin{array}{lll}
0,65 & 0,15 & 0,20 \\
0,30 & 0,55 & 0,15 \\
0,35 & 0,20 & 0,45
\end{array}\right)
$$

the quote of those 3 products for the students of our university will be presented like the following vector:

$\mathrm{T} 1=(0,65 ; 0,55 ; 0,45)$

after computing the results of the first year, the quote of those 3 products for the students of our university is:

$\mathrm{T} 2=(0,745 ; 0,49 ; 0,415)$

after the second year, the vector is:

$\mathrm{T} 3=(0,7765 ; 0,46425 ; 0,40925)$

in the third year, the vector is:

$\mathrm{T} 4=(0,7872375 ; 0,4536625 ; 0,4091)$

based on these results we will create a table showing the evolution of these 3 products in a 4 years band.

\begin{tabular}{|c|c|c|c|c|}
\hline & First year & $\begin{array}{c}\text { Second } \\
\text { year }\end{array}$ & $\begin{array}{c}\text { Third } \\
\text { year }\end{array}$ & $\begin{array}{c}\text { Forth } \\
\text { year }\end{array}$ \\
\hline $\begin{array}{c}\text { Smart } \\
\text { Phones }\end{array}$ & 0,65 & 0,745 & 0,7765 & 0,7872375 \\
\hline PDA & 0,55 & 0,49 & 0,46425 & 0,4536625 \\
\hline $\begin{array}{c}\text { Mobil } \\
\text { Phones }\end{array}$ & 0,45 & 0,415 & 0,40925 & 0,4091 \\
\hline
\end{tabular}

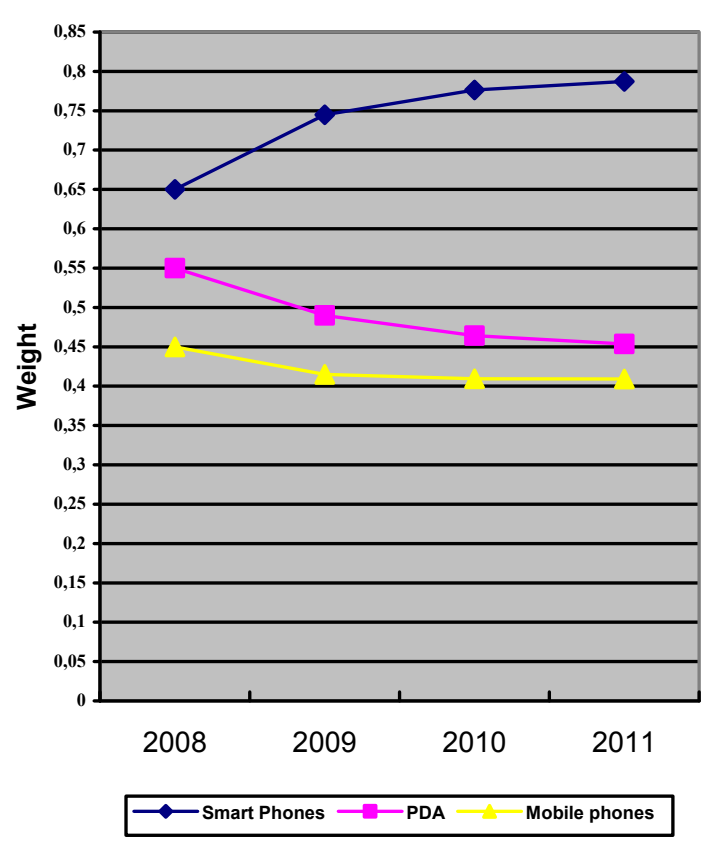


The results show that students reoriented towards Smart Phones, products that are in an ascending trend, from $60 \%$ to $80 \%$. The PDAs have been losing trend for the last 4 years, so appears that students reoriented towards the other 2 products, for the entire analyzed period. The "mobile phones" market had decreased in the first 2 years and then has been constant.

As a conclusion, the e-learning platform that we are proposing should use Smart Phones because, based on our 4 years forecast, that they will have the biggest success among students within our university.

\section{REFERENCES:}

[1] S.V. Nicolaescu, COMUNICATII MOBILE, GENERATIILE 3G ŞI 4G, 2006

[2] H.A. Grebla, G.S. Chis L.M. Stanca and C. Ciumas E-Learning Platform for Student Recruitment and Retention, Informatics Education in Europe IEEII 2007, South-East European Research Centre, P. 342-351, 2007

[3] http://www.wikipedia.com

[4] http://www.vodafone.ro

[5] http://www.orange.ro

[6] L. Luna, Led by vendor partnership ip enters wireless forefront, February, 2002, http://telephonyonline.com

[7] O.E. Martikainen, Complementarities creating substitutes possible paths towards $3 \mathrm{G}$, WLAN/WiMAX and ad hoc networks, P. 21-32, 2006

[8] S.M. Cheng, P. Lin, G.H. Tu, L.C. Fu and C.F. Liang, An intelligent GGSN dispatching mechanism for UMTS, http://sciencedirect.com

[9] ***Juniper Networks - Building Next-Generation Mobile Packet Core Networks, White Paper, 2007

[10] P. Lin and G.H. Tu, An Improved GGSN Failure Restoration Mechanism for UMTS, P. 91-103,2006

[11] 3GPP, 3rd Generation Partnership Project; Radio Interface Protocol Architecture. Technical Report Technical Specification 3G TS 25.301version 3.4.0 (2000-03) (2000)

[12] 3GPP, 3rd Generation Partnership Project; Technical Specification Group Services and System Aspects; Architecture Principles for elease 2000; Release 2000. Technical Report Technical Specification 3G TR 23.821 version 1.0.1 (2000-07) (2000)

[13] 3GPP, 3rd Generation Partnership Project; Technical Specification Group Core Network; Restoration Procedures; Release 5. Technical Report Technical Specification 3G TS 23.007 version 4.0.0 (2001-03),(2001)

[14] 3GPP, 3rd Generation Partnership Project; Technical Specification GroupCore Network; General Packet Radio Service (GPRS); GPRS Tunneling Protocol (GTP) across the Gn and Gp Interface; Release 5. Technical Report Technical Specification 3G TS 29.060 version 5.0.1(2002-01) (2002).

[15] 3GPP, 3rd Generation Partnership Project; Technical Specification Group Services and Systems Aspects; General Packet Radio Service (GPRS); Service Description; Stage 2; Release 5. Technical Report Technical Specification 3G TS 23.060 version $5.0 .0(2002-01)(2002)$.
[16] 3GPP, 3rd Generation Partnership Project; Technical Specification Group Services and System Aspects; IP Multimedia Subsystem (IMS)

[17] C. Ratiu-Suciu, F. Luban, D. Hincu and N. Ciocoi, Modelare Economica, studiu de caz, teste, ISBN:978-9730594-928-0, 2007

[18] ***Study case made on admission of students in the faculty FSEGA: $2005 / 2008$

[19] D. Schwab and R. Bunt, Characterizing the use of a campus wireless network, IEEE INFOCOM (2004).

[20] X. Meng, S. Wong, Y. Yuan and S. Lu, Characterizing flows in large wireless data networks, ACM Mobicom (2004).

[21] A. Balachandran, G.M. Voelker, P. Bahl and P. Venkat Rangan, Characterizing user behavior and network performance in a public wireless LAN, Sigmetrics Performance Evaluation. Review 30 (1) (2002) 195-205.

[22] T. Henderson, D. Kotz and I. Abyzov, The changing usage of a mature campus-wide wireless network, in: Proceedings of ACM Mobicom,ACM Press, 2004, pp. 187-201.

[23] J. Ridoux, A. Nucci, and D. Veitch, Seeing the difference in IP traffic: wireless versus wireline, Proceedings of IEEE InfoCom (2006).

[24] M. Iftikhar and B. Landfeldt, An analytical model based on G/M/1 with self-similar traffic input and non-preemptive priority service discipline,Technical Report, ANRG, School of IT, University of Sydney, Nov. 2007.

[25] 3GPP, Universal mobile telecommunication system (UMTS); QoS Concepts and Architecture, TS23.107V6, March 2004.

[26] K. Venken, J. De Vriendt and D. De Vleeschauwer, Designing a DiffServcapable IP-backbone for the UTRAN, IEEE 2nd International Conference on $3 \mathrm{G}$ Mobile Communication Technologies, 26-28 March 2001, pp. 47-52.

[27] S. Maniatis, C. Grecas and I. Venieris, end-to-end QoS issues over next generation mobile internet, IEEE Symposium on Communication and Vehicular Technology, 2000, SVCT-2000, 19 Oct, 2000, pp. 150-154.

[28] P. Newman, Netillion Inc. in search of the all-IP mobile network, IEEE Communication Magazine 42 (12) (2004) S3-S8. (doi:10.1109/MCOM.2004.1367552)

\section{AUTHORS}

G.S. Chis, PhD. Student Babes Bolyai University, Faculty of Economics and Business Administration, Informatics Department Address: Street Teodor Mihali, No.58-60. Email: george.chis@econ.ubbcluj.ro

H. Grebla, PhD. Student, Babes Bolyai University, Faculty of Mathematics and Computer Science CS Department. Email: horea@cs.ubbcluj.ro

L. Stanca, Lecturer PhD. Babes Bolyai University, Faculty of Economics and Business Administration, Informatics Department Address: Street Teodor Mihali, No.58-60. Email: liana.stanca@econ.ubbcluj.ro

Manuscript received 22 October 2008. Published as submitted by the authors. 